\title{
Role of Four Layer Compression Dressings in Management of Chronic Venous Ulcers
}

\author{
Luv Luthra ${ }^{1} \quad$ Rajendra Prasad ${ }^{1} \quad$ Ranjith Kumar $^{1} \quad$ Nivedita Mitta ${ }^{1} \quad$ Tinku Varghese $^{1}$ \\ ${ }^{1}$ Department of Vascular Surgery, MS Ramaiah Medical College, \\ Bengaluru, Karnataka, India \\ Address for correspondence Luv Luthra, MBBS, MS, MCh, \\ Department of Vascular Surgery, MS Ramaiah Medical College, MS \\ Ramaiah Nagar, Mathikere, Bengaluru 560054, Karnataka, India \\ (e-mail: drluv.luthra@gmail.com).
}

Int J Recent Surg Med Sci 2019;5:42-45

\begin{abstract}
Introduction Nonhealing venous ulcers are one of the most common forms of lower extremity ulcers in the present population. It is cumbersome to treat and is associated with high-morbidity and immense treatment expenses. The current treatments include compression therapy. Four-layer compression dressings have proven to be an effective treatment for venous ulcers.

Objective This study aimed to evaluate the efficacy of four-layer compression dressings and to study the rate of healing and duration of treatment with four-layer compression dressings.

Materials and Methods A prospective randomized study conducted at MS Ramaiah Medical college which included 70 patients who completed the course of weekly dressings depending on the size of ulcer. The regular four-layer dressings were done by a trained podiatrist in vascular outpatient department (OPD) once a week. The area of the ulcer was calculated using the modified Gilmen formula.

Results A total of 70 patients who were compliant with the treatment were includ-

\section{Keywords}

- compression dressings

- four-layer dressing

- venous ulcer ed in the study. A considerable percentage (74\%) of patients were male and all the ulcers were located at the gaiter area. Most belonged to the age group between 41 to 50 years (25\%). The healing rate of ulcers at the end of 4,8 , and 12 weeks were 46.87 , 28.12 , and $25 \%$, respectively. At the end of 12 weeks, all the ulcers healed.
\end{abstract}

\section{Introduction}

Venous leg ulcers are defined as open skin lesions between the knee and ankle joint which occur in the presence of venous disease. According to the revised Clinical-Etiological-Anatomical-Pathophysiological (CEAP) classification, a venous ulcer is defined as full-thickness defect of the skin, most frequently in the ankle region, which fails to heal spontaneously and is sustained by chronic venous disease. Venous ulcers are clinical manifestations of chronic venous insufficiency and occur as a result of venous hypertension and calf muscle pump abnormalities. ${ }^{1}$
This is one of the most common causes of leg ulcers (60-80\%). The venous ulcers are characterized by a cyclical pattern of healing and recurrence. Recurrence rates of 45 to $70 \%$ have been reported. ${ }^{2}$

Nonhealing, long-standing venous ulcers were traditionally treated with limb elevation, daily dressings, mechanical compression therapy, and ankle physiotherapy.,4 The four-layer bandage dressing that provides a subankle pressure of $40 \mathrm{~mm} \mathrm{Hg}$ has revolutionized the treatment of nonhealing venous ulcers. ${ }^{5}$

We present our experience with 4-layer compression dressing as an outpatient treatment for chronic venous ulcers.
License terms Update Society 


\section{Materials and Methods}

It is a prospective, observational study conducted at the MS Ramaiah Medical College, Bengaluru, from July 2018 to July 2019. A total of 70 patients with nonhealing chronic venous ulcer who underwent 4-layer compression dressings were included after proper written and informed consents. Patients with arterial insufficiency (ankle brachial pressure index $[\mathrm{ABPI}]<0.9)$, diabetic. and arterial ulcers were excluded from the study. The 4-layer dressings were done by a trained podiatrist in all the patients on weekly basis. In patients with exudative wounds, silver-impregnated foam dressing was applied after cleaning of wounds and prior to 4-layer dressing. All patients received antibiotics as per the culture sensitivity reports. The patients who were not compliant with the treatment were excluded.

Modified Gilmen formula was used to calculate the area of ulcer in the follow therapy:

Modified Gilman Index $(\mathrm{cm}) \mathrm{D}=\Delta \mathrm{S} / \mathrm{p}=\mathrm{SI}-\mathrm{SF} /(\mathrm{CF}+\mathrm{CI}) / 2$

$$
=2(\mathrm{SI}-\mathrm{SF}) / \mathrm{CF}+\mathrm{CI}
$$

SI: Initial total area $\left(\mathrm{cm}^{2}\right)$

SF: final wound total area after two months $\left(\mathrm{cm}^{2}\right)$

$\mathrm{CI}$ : initial circumference $(\mathrm{cm})$

CF: final wound circumference after two months $(\mathrm{cm})$

$\Delta \mathrm{S} \%$ : percentage change of the total surface area (\%)

$\Delta \mathrm{S} \%=(\mathrm{SI}-\mathrm{SF}) \times 100 \% \mathrm{SI}$
Patients were followed up every 4, 8, and 12 weeks for partial or complete healing of ulcer.

\section{Statistical Analysis}

Continuous variables were presented as mean for parametric data and median if the data are nonparametric or skewed. Student $t$-test was applied for calculation of statistical significance whenever the data followed normative distribution. The Mann-Whitney test was applied whenever data followed non-normative distribution. Categorical variables were expressed as frequencies and percentages. Nominal categorical data between the groups was compared using Chi-square test or Fisher's exact test as appropriate. $p<0.05$ was taken to calculate statistical significance.

\section{Results}

The majority of the patients were between 41 to 50 years of age. A significant percentage (74\%) of patients in our study were males (-Fig. 1) and pain was the most common symptom in $68.5 \%$ patients followed by edema in $51.4 \%$ patients.

Maximum number of ulcers (28.57\%) ranged between 11 to $20 \mathrm{~cm}^{2}$ and $21.14 \%$ patients had ulcers of 21 to $30 \mathrm{~cm}^{2}$ (-Table 1).



Fig. 1 Age distribution.

Table 1 Area of ulcer

\begin{tabular}{|l|l|l|}
\hline Area of ulcer $\left(\mathrm{cm}^{2}\right)$ & No. of patients & Percentage (\%) \\
\hline$<10$ & 12 & 17.14 \\
\hline $11-20$ & 20 & 28.57 \\
\hline $21-30$ & 15 & 21.14 \\
\hline $31-40$ & 10 & 14.28 \\
\hline $41-50$ & 08 & 11.42 \\
\hline $51-60$ & 03 & 4.28 \\
\hline $61-70$ & 02 & 2.85 \\
\hline
\end{tabular}

\section{Discussion}

Chronic venous insufficiency is the most common cause of venous ulcer. The cornerstone of treatment of this condition involves reducing the ambulatory limb venous pressures, ,6-10 and four-layered dressings have been shown to bring down the ambulatory venous pressures., ${ }^{5,-11}$ These four-layer dressings have a proven role in wound healing. .,10-12 $^{-12}$

The purpose of this study was to assess the efficacy of four-layered dressing in the outpatient setting, as venous 
ulcers can not only be a major debilitating factor in the patient's life physically and emotionally but also financially burdening the patient and his or her family. A proven outpatient means of management can definitely improve the patient's well-being. Four-layered dressings include an inner-most sterile absorbant gauze dressing which protects the ulcer. The first layer is a soft cotton roll which pads the leg and also absorbs the exudates from the ulcer. The second layer is a supportive crepe bandage layer which conforms to the leg curvature. These two layers do not necessarily provide much compression. The third layer is the elastic compression bandage which provides pressures of approximately $17 \mathrm{~mm} \mathrm{Hg}$. The fourth layer is the cohesive bandage which adds on an additional $23 \mathrm{~mm} \mathrm{Hg}$, making it a total of $40 \mathrm{~mm}$ $\mathrm{Hg}$ pressure at the ankle and reducing to $17 \mathrm{~mm} \mathrm{Hg}$ at the knee. In addition, this four-layer compression bandage maintains graduated, sustained, and effective compression for a longer duration even up to a week after application. ${ }^{11,13,14}$

Extended wear time of the dressing leads to drainage of the venous pool, thereby reducing local venous hypertension. Compression therapy reduces edema, reverses venous hypertension, and improves calf muscle pumping function. ${ }^{15}$ Topical agents and special silver-impregnated dressings are used to decrease the bacterial load in the wound and provide a moist healing environment for dry wounds, or absorb the exudate in wounds with a lot of drainage. In our case, we used silver-impregnated dressings in patients with excessive discharge from the wounds. The basis of this use being silver dressings are topical wound care products derived from ionic silver. ${ }^{16}$ These products release a steady amount of silver to the wound and provide antimicrobial or antibacterial action.
The silver is activated from the dressing to the wound's surface, based on the amount of exudate and bacteria in the wound. Silver dressings are available as foam dressings, hydrocolloids, barrier layers, and charcoal cloth dressings.

One of the major drawbacks of any form of compression dressing is reduced compliance due to wearer discomfort. ${ }^{17}$ This can be negated only with patient education and regular motivation. Other drawbacks being correct application of compression bandages need expertise, older debilitated patients with comorbidities find it difficult to use compression stockings, and peripheral vascular compromise in patients with mixed-arterial venous ulcers with low-ankle brachial index (ABI)

In our study, we focused mostly on patient compliance and technique of application. We were fortunate to have a trained podiatrician who played a major role in the above two factors. With the infrastructure at hand, we managed to achieve full healing of all our ulcers over 12 weeks, almost $50 \%$ of which were healed in the first 4 weeks (-Table 2, - Fig. 2).

\section{Conclusion}

Chronic venous ulcers as described have a debilitating effect on the patients' quality of life. Four-layer compression dressing has been proven to be a simple, cost effective out-patient treatment for these patients. As majority of the patients are young males, the lone bread earners of the family a weekly four layer dressing treatment has good compliance rates in these patients. The limitation of our study was a small sample size, but the effectiveness of the four layer dressings in healing of chronic venous ulcers cannot be denied.

Table 2 Time of healing

\begin{tabular}{|l|l|l|l|}
\hline No. of weeks & Partially healed (\%) & Completely healed (\%) & Total (\%) \\
\hline At 4 wk & 28.12 & 18.75 & 46.87 \\
\hline At 8 wk & 15.62 & 12.50 & 28.12 \\
\hline At 12 wk & 9.3 & 15.62 & 25 \\
\hline
\end{tabular}

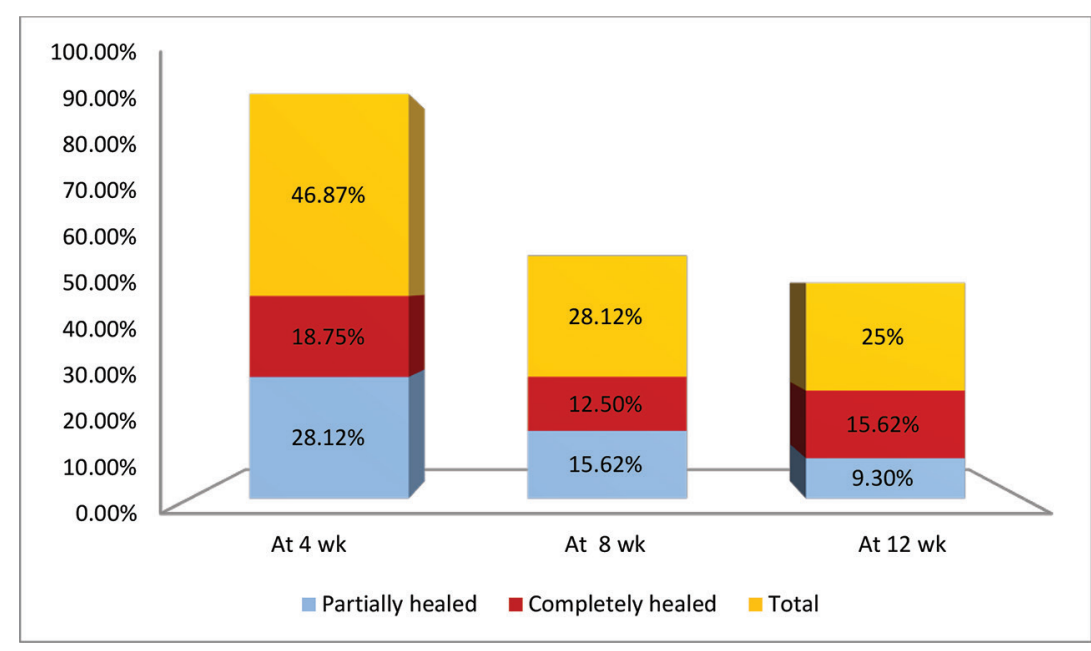

Fig. 2 Status of wounds at different time periods of observation. 


\section{Conflict of Interest}

None declared.

\section{References}

1 Delis KT, Nicolaides AN, Wolfe JH, Stansby G. Improving walking ability and ankle brachial pressure indices in symptomatic peripheral vascular disease with intermittent pneumatic foot compression: a prospective controlled study with one-year follow-up. J Vasc Surg 2000;31(4):650-661

2 Fletcher A, Cullum N, Sheldon TA. A systematic review of compression treatment for venous leg ulcers. BMJ 1997;315(7108):576-580

3 Sarkar PK, Ballantyne S. Management of leg ulcers. Postgrad Med J 2000;76(901):674-682

4 Rudolph D. Standards of care for venous leg ulcers: compression therapy and moist wound healing. J Vasc Nurs 2001;19(1):20-27

5 O'Meara S, Tierney J, Cullum N, et al. Four layer bandage compared with short stretch bandage for venous leg ulcers: systematic review and meta-analysis of randomised controlled trials with data from individual patients. BMJ 2009;338:b1344

6 Vowden K, Vowden P. Anatomy, physiology and venous ulceration. J Wound Care 1998;7(7 Suppl):1-5

7 Blair SD, Wright DD, Backhouse CM, Riddle E, McCollum CN. Sustained compression and healing of chronic venous ulcers. BMJ 1988;297(6657):1159-1161
8 Stacey M, Falanga V, Marston W, et al. Compression therapy in the treatment of venous leg ulcers. Nurs Times 2002;98(36):39-43

9 Partsch H. Compression therapy of the legs. A review. J Dermatol Surg Oncol 1991;17(10):799-805

10 O'Meara S, Cullum N, Nelson EA, Dumville JC. Compression for venous leg ulcers. Cochrane Database Syst Rev 2012;11:CD000265

11 Moffatt C, Stubbings N. The Charing Cross approach to venous ulcers. Nurs Stand Spec Suppl 1990;10(10):6-9

12 Kistner RL, Shafritz R, Stark KR, Warriner RA III. Emerging treatment options for venous ulceration in today's wound care practice. Ostomy Wound Manage 2010;56(4):E1-E11

13 MoffattC. Four-layer bandaging: from concept to practice. worldwide wounds.com. Available at: http://www.worldwidewounds.com/2005/march/Moffatt/Four-Layer-BandageSystem-Part2.html. Accessed February 14, 2020

14 Moffatt C. Four-layer bandaging: from concept to practice. Int J Low Extrem Wounds 2002;1(1):13-26

15 Frykberg RG, Banks J. Challenges in the treatment of chronic wounds. Adv Wound Care (New Rochelle) 2015;4(9): 560-582

16 Hess CT. Shapes by PolyMem Silver Quadrafoam Dressings in Clinical Guide: Skin and Wound Care 6th edition. Ambler, PA: Lippincott Williams \& Wilkins. 2007;234-235

17 Nair B. Compression therapy for venous leg ulcers. Indian Dermatol Online J 2014;5(3):378-382 